specific medical conditions or services and using them as markers. Changes in productivity may vary between conditions, a finding that could help inform future decisions on where to allocate resources.

Furthermore, better data on the process and outcome of care should be collected routinely from patients. Some high quality clinical databases already include such data, and these are not being fully exploited. ${ }^{6}$ Data collection systems are currently being tested in other clinical areas, such as elective surgery. ${ }^{5}$ Sophisticated computer models based on rigorous research evidence could be used more widely to provide more accurate estimates of the relative contributions that prevention, cure, rehabilitation, and even interventions outside health care make to improvements in health. This has already been shown for coronary heart disease. ${ }^{7}$ Lastly, the NHS needs better data on public valuations of health derived from regular large scale surveys. This information could replace the current arbitrary estimates, thus ensuring that changes to the estimates are not influenced by political necessity.

Yet how meaningful will the results be, even with the adoption of this more focused approach? We will still have to rely on some assumptions (such as the contribution of health services to improvements in people's health). In addition, interpretation of the estimates is a value judgement-what constitutes a satisfactory improvement in productivity? The Department of Health currently suggests an improvement of $1.5 \%$ a year, but this figure is simply based on the level adopted by the education sector. And what if improvements in productivity based on clinical outcomes are accompanied by a worsening in the humanity of care, such that patients become increasingly critical of their experiences of health care?
Another concern for the government is the extent to which improvements in productivity are possible. Health care has reached or even gone beyond the "flat of the curve," such that each successive extra investment inevitably results in less health gain. Improvements in productivity will depend largely, therefore, on delivering established services more efficiently, rather than on increasing the effectiveness of treatments.

The Department of Health recognises such theoretical and practical concerns but, despite this, current political necessity may over-ride considered judgment. Arguments about the productivity of the NHS will almost certainly feature strongly over the next few years and will be a central battleground before the next general election, as each party claims to be the better manager of healthcare expenditure.

Nick Black professor of health services research (nick.black@lshtm.ac.uk)

John Browne senior lecturer in outcomes measurement John Cairns professor of health economics

Health Services Research Unit, London School of Hygiene and Tropical Medicine, London WC1E 7HT

1 Timmins N. NHS faces spending squeeze. Financial Times 2006 January 16.

Office of National Statistics. Public service productivity: health. London: Office of National Statistics, October 2004

Atkinson AB. Atkinson review of government output and productivity for the national accounts: final report. Basingstoke: Palgrave Macmillan, 2005.

4 Office of National Statistics. Public service productivity: health. London: Office of National Statistics, February 2006.

5 Department of Health. Healthcare output and productivity: accounting for Department of Health. Healthcare output and produ
quality change. London: Department of Health, 2005.

quality change. London: Department of Health, 2005.
Black N, Barker M, Payne M. Cross-sectional survey of multicentre cliniBlack N, Barker M, Payne M. Cross-sectional survey of multic
cal databases in the United Kingdom. BMJ 2004;328:1478-81.

Babad H, Sanderson C, Naidoo B, White I, Wang D. Modelling primary prevention strategies for coronary heart disease. Health Care Manag Sc 2002;5:269-74.

\title{
Postoperative nausea and vomiting
}

\section{Metaclopramide with dexamethasone works and has few side effects}

Research p 324
$\mathrm{F}$ ifteen years ago Kapur described postoperative nausea and vomiting as the "big, little problem," a description that still applies despite the best efforts of doctors and drug companies. In this issue of the $B M J$, Wallenborn and colleagues revisit the use of metoclopramide to prevent postoperative nausea and vomiting. ${ }^{2}$ In the United Kingdom, metoclopramide is no longer a popular choice for prophylaxis or treatment. This is because the standard $10 \mathrm{mg}$ dose is not very effective ${ }^{3}$; metoclopramide has unpleasant side effects such as extrapyramidal symptoms, especially with repeated doses; and it has been supplanted by newer agents that are more expensive but have fewer complications.

The likelihood of postoperative nausea and vomiting is increased by several factors including the type of surgery (for example, laparoscopic, gynaecological, and ophthalmic surgery), certain anaesthetic drugs including volatiles and opioids, patient factors including female sex, a history of postoperative nausea and vomiting, and non-smoking status. ${ }^{4}$ The most effective treatment is usually a combination of agents that target different pathways or receptors. ${ }^{5}$ These include antihistamines, anticholinergics, antidopaminergics, 5-hydroxytryptamine receptor $\left(5-\mathrm{HT}_{3}\right)$ antagonists, and drugs with poorly understood modes of action such as dexamethasone. ${ }^{6}$ A popular combination in the UK at present is a $5-\mathrm{HT}_{3}$ antagonist such as ondansetron or tropisetron combined with dexamethasone, with the addition of agents from another class such as promethazine or cyclizine for rescue or for resistant cases. ${ }^{7}$

Wallenborn and colleagues have taken the innovative step of revisiting the effects of metoclopramide in a randomised trial using the standard $10 \mathrm{mg}$ dose and also doses of $25 \mathrm{mg}$ and $50 \mathrm{mg}$ (doses that will be unfamiliar to most doctors in the UK). Metoclopramide was added to dexamethasone in more than 3000 patients having elective surgery. Both the $25 \mathrm{mg}$ and $50 \mathrm{mg}$ combinations were strikingly effective in reducing early postoperative nausea and vomiting, and $50 \mathrm{mg}$ also prevented late nausea and vomiting. Side effects, 
mostly hypotension and tachycardia, were few. The incidence of dyskinesia and extrapyramidal side effects was also surprisingly low $-0.4 \%$ in the $25 \mathrm{mg}$ group and $0.8 \%$ in the $50 \mathrm{mg}$ group (number needed to harm 156 for both doses).

Newer drugs such as $5-\mathrm{HT}_{3}$ antagonists have undoubtedly improved outcomes; a neurokinin receptor antagonist (aprepitant) has also been introduced in the UK for the treatment of chemotherapy induced nausea and vomiting. ${ }^{8}$ However, the mechanism underlying postoperative nausea and vomiting is so complex that a universal panacea is unlikely, and a multimodal approach is best for both prevention and treatment. In this regard, the optimum dose of metoclopramide combined with dexamethasone offers another option for prevention of nausea and vomiting or as an adjunct or alternative to existing treatment.

A head to head trial of metoclopramide and dexamethasone versus a $5-\mathrm{HT}_{3}$ antagonist combined with dexamethasone would be the next logical step. In the meantime, the trial by Wallenburg et al supports metoclopramide as an option for the prevention and treatment of postoperative nausea and vomiting. This use of metoclopramide would probably result in considerable cost saving compared with the newer $5-\mathrm{HT}_{3}$ antagonists, such as palonosetron, despite their longer duration of action.
Finally, Wallenborn and colleagues also found that regular consumption of alcohol protects against postoperative nausea and vomiting. This finding adds to the debate about why certain factors, such as smoking, protect against postoperative nausea and vomiting. ${ }^{5}$

\section{Brian Sweeney consultant}

(bpsween@aol.com)

Poole and Royal Bournemouth Hospital, Bournemouth BH7 7DW

1 Kapur PA. The big, little problem. Anaesth Analg 1991;72:243-5.

2 Wallenborn J, Gelbrich G, Bulst D, Behrends K, Wallenborn H, Rohrbach $\mathrm{A}$, et al. Prevention of postoperative nausea and vomiting by metoclopraA, et al. Prevention of postoperative nausea and vomiting by metoclopramide combined with dexamethaso
multicentre trial. $B M J$ 2006:333:324-7.

3 Henzi I, Walder B, Tramer MR. Metoclopramide in the prevention of postoperative nausea and vomiting: a quantitative systematic review of randomised, placebo-controlled studies. BrJ Anaesth 1999;83:761-71.

4 Apfel CC, Greim CA, Haubitz I, Goepfert C, Usadel J, Sefrin P, et al. A risk score to predict the probability of postoperative vomiting in adults. Acta Anaesth Scand 1998;42:495-501.

5 Habib AS, Gan TJ. Combination therapy for postoperative nausea and vomiting: a more effective prophylaxis? Ambulatory Surg 2001:9:59-71.

6 Gan TJ, Meyer T, Apfel CC, Chung F, Davis PJ, Eubanks S, et al. Consenans 1., Meyer T, Apfel CC, Chung F, Davis PJ, Lubanks S, et al. Consensus guidelines for managing postoperative nausea and vomiting. Anesth

Apfel CC, Kortilla K, Abdalla M, Kerger H, Turan A, Vedder I, et al. A factorial trial of six interventions for the prevention of postoperative nausea and vomiting. $N$ Engl J Med 2004;350:2441-51

8 Aapro M, Johnson J. Chemotherapy-induced emesis in elderly cancer patients: the role of 5-HT3-receptor antagonists in the first 24 hours. Gerontology 2005;51:287-96.

9 Sweeney BP. Why are smokers protected against PONV [editorial]? Br J Anaesth 2002;89:1-4.

\section{Heat waves and health protection}

\section{Focus on public health, social care, and building regulations}

$\mathrm{T}$ his summer Europe has again been affected by a major heat wave and England triggered its heat wave response plan for the first time. ${ }^{1}$ In 2003, the impact of the heat wave in central France was unprecedented, with more than 14000 excess deaths attributed to the 20 day event. ${ }^{2}$ This year, France has reported considerably fewer deaths, and the authorities can claim some credit for effective public health intervention. The United Kingdom experienced a more severe heat wave than in 2003, but the full impact on health is not yet known. Schools, offices, hospitals, and the transport infrastructure were all affected badly. Although much is known about the regulation of body temperature in healthy fit adults, little research has been undertaken on the social and environmental determinants of heat related mortality. People with psychiatric disorders, depression, cardiovascular and cerebrovascular conditions, ${ }^{3}$ and diabetes ${ }^{4}$ are at high risk of death during a heat wave. Specific drugs, such as neuroleptics and anticholinergics, can also impair thermoregulation. ${ }^{1}$ Susceptible people may be socially isolated and may have a mental illness or disability that limits their ability to care for themselves. The perception of ambient temperature is also poorer in elderly people, who do not always realise that they are becoming too hot. ${ }^{5}$ The passive dissemination of advice on heat avoidance is insufficient for health protection, and vulnerable people need to be actively identified and cared for. ${ }^{6}$
Public health measures implemented in Europe after 2003 have centred almost exclusively on heat health warning systems that forecast high risk weather conditions to trigger public warnings. ${ }^{7}$ Level 3 of the heat wave plan for England, triggered in early July, requires primary care trusts to "Commission additional care and support, involving at least daily contact, as necessary for at-risk individuals living at home." But there is much confusion about identifying people at risk as well as the specific advice to be given. Cities in Italy are the most advanced in identifying and contacting vulnerable people at home during a heat wave. So far, no heat health system has been formally evaluated, and the effectiveness of individual interventions is unknown. ${ }^{6}$

The impact of heat waves also reveals important lessons about the care of the elderly and dispossessed in our society-in both the community and social care. The impact of heat waves in the United States is mostly confined to poor elderly people living in urban areaswho cannot afford air conditioning-and to the homeless. Elderly people in nursing and residential homes are more frail than those living independently or with family. Although such people have a higher risk of death than the general population, they should not have a higher risk of heat related death. Heat illness can be prevented by keeping the patient cool, hydrated, and with adequate salt balance. In the UK, air conditioning is rare in clinical settings, and hospital 